\title{
Subtropical Mode Water Variability in a Climatologically Forced Model in the Northwestern Pacific Ocean
}

\author{
Elizabeth M. Douglass And STEVEn R. JAYNE \\ Woods Hole Oceanographic Institution, Woods Hole, Massachusetts \\ SYNTE PEACOCK AND FRANK O. BRYAN \\ National Center for Atmospheric Research, Boulder, Colorado \\ MATHEW E. MALtRUd \\ Los Alamos National Laboratory, Los Alamos, New Mexico
}

(Manuscript received 1 June 2010, in final form 5 August 2011)

\begin{abstract}
A climatologically forced high-resolution model is used to examine variability of subtropical mode water (STMW) in the northwestern Pacific Ocean. Despite the use of annually repeating atmospheric forcing, significant interannual to decadal variability is evident in the volume, temperature, and age of STMW formed in the region. This long time-scale variability is intrinsic to the ocean. The formation and characteristics of STMW are comparable to those observed in nature. STMW is found to be cooler, denser, and shallower in the east than in the west, but time variations in these properties are generally correlated across the full water mass. Formation is found to occur south of the Kuroshio Extension, and after formation STMW is advected westward, as shown by the transport streamfunction. The ideal age and chlorofluorocarbon tracers are used to analyze the life cycle of STMW. Over the full model run, the average age of STMW is found to be $4.1 \mathrm{yr}$, but there is strong geographical variation in this, from an average age of $3.0 \mathrm{yr}$ in the east to $4.9 \mathrm{yr}$ in the west. This is further evidence that STMW is formed in the east and travels to the west. This is qualitatively confirmed through simulated dye experiments known as transit-time distributions. Changes in STMW formation are correlated with a large meander in the path of the Kuroshio south of Japan. In the model, the large meander inhibits STMW formation just south of Japan, but the export of water with low potential vorticity leads to formation of STMW in the east and an overall increase in volume. This is correlated with an increase in the outcrop area of STMW. Mixed layer depth, on the other hand, is found to be uncorrelated with the volume of STMW.
\end{abstract}

\section{Introduction}

Mode waters are thick subsurface layers with constant temperature and potential vorticity. These are formed when a deep mixed layer caused by strong winter winds is subducted beneath the seasonal thermocline, while retaining its homogeneous qualities. In the Northern Hemisphere, both the Atlantic and Pacific Oceans have mode waters near where the western boundary current of the subtropical gyre separates from the coast. In the North

Corresponding author address: Elizabeth M. Douglass, Woods Hole Oceanographic Institution, MS \#29, 266 Woods Hole Rd., Woods Hole, MA 02543.

E-mail: edouglass@whoi.edu
Atlantic, this is known as Eighteen Water (Worthington 1959); in the North Pacific, it is referred to as subtropical mode water (STMW) (Masuzawa 1969). STMW has been studied extensively, through both modeling studies and observational analysis to examine its formation, its characteristics, and its variability (e.g., Suga et al. 1989; Suga and Hanawa 1995b). Interannual to decadal variability has been noted in many previous analyses of STMW (Oka 2009; Suga and Hanawa 1995a; Taneda et al. 2000). Often, this variability is attributed to variability in atmospheric forcing, such as changes in the intensity of the monsoon system (Suga and Hanawa 1995a). Qiu and Chen (2006) attribute variability in STMW formation to changes in the dynamic state of the Kuroshio. However, the changes in the dynamic state of the Kuroshio can be 


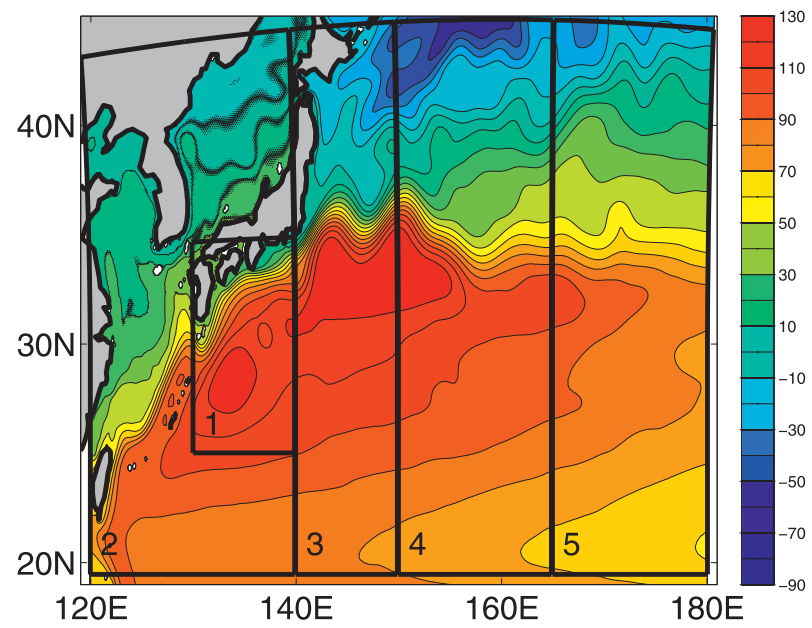

FIG. 1. Area of study: contours show the mean SSH $(\mathrm{cm})$ over a 100-yr model run; the contour interval is $10 \mathrm{~cm}$. Numbered boxes indicate the geographical subsections used in the analysis.

traced back to large-scale wind forcing (Qiu and Chen 2005). The present study will look closely at the characteristics and variability of STMW, using a model forced with an annually repeating atmosphere to discern the intrinsic oceanic variability of the system, as opposed to variation arising from changing buoyancy flux and wind stress. The goal of the analysis is to quantify some of the mean properties of STMW and their spatial variability and to determine how much of the temporal variability observed in these properties is due to intrinsic oceanic variability demonstrated in this model, rather than atmospheric variability which is excluded from the model output.

The paper is organized as follows: Section 2 contains a description of the model used in this analysis. Section 3 provides the definition of subtropical mode water and describes the variation of its volume, thickness, and core properties, as well as its formation and subsequent advection. Section 4 looks into the variability of the age of mode water, using the ideal age, chlorofluorocarbons (CFCs), and transit-time distribution (TTD) analysis. Section 5 discusses the time variability of all these properties and looks into possible forcing associated with significant interannual signals. Section 6 provides a discussion and conclusions.

\section{Model description}

The model used here is the Parallel Ocean Program (POP), an ocean general circulation model that solves the three-dimensional primitive equations for ocean dynamics (Smith and Gent 2002). This setup is the same as that used in Maltrud et al. (2010), including the use of a tripole grid. Instead of a singularity at the North Pole, this grid has two singularities in the Northern Hemisphere, both located over land (North America and Asia), to eliminate singularities within the ocean (Murray 1996). The model was run globally for 120 years with annually repeating surface atmospheric conditions, downward radiative fluxes, and precipitation prescribed from a climatology blending National Center of Environmental Prediction (NCEP) reanalysis products and remote sensing products, known as normal-year forcing (Large and Yeager 2009). Air-sea heat and moisture fluxes are computed using the prescribed atmospheric state and the model-predicted sea surface temperature through the standard bulk formulae. Intrinsic oceanic variability leads to SST variations, which changes the calculated heat and moisture fluxes on nonseasonal time scales, but this variation is small in comparison to the seasonal cycle. The model has 42 vertical levels and approximately $1 / 10^{\circ}$ horizontal spacing in both latitude and longitude, allowing resolution of mesoscale features such as eddies. Monthly averaged fields of temperature; salinity; sea surface height (SSH); and zonal, meridional, and vertical velocity are stored as output. Several additional diagnostic fields such as ideal age, potential vorticity, CFC-11, and TTDs are also stored. Years 0 through 19 were considered spinup, and output was available for years 20 119 for temperature, salinity, $\mathrm{SSH}$, ideal age, and all velocity fields. Potential vorticity fields are only available for years 48-119. The model was run globally, but this analysis is limited to the North Pacific. The mean SSH in the study region is shown in Fig. 1.

Ideal age is a model variable that will be used extensively in this analysis. The ideal age is a tracer field used to determine ventilation time scales (England 1995). At the surface, the ideal age of any given water parcel is set to zero. Everywhere else, ideal age increments with time. Thus, the ideal age is the time since a given water parcel was last ventilated. The principal caveat when using this metric has to do with reaching equilibrium. Since ideal age can never be larger than the length of time for which the model has been running, water masses such as bottom water, which have ventilation time scales on the order of thousands of years, will not have time to reach equilibrium during the short (120 yr) model run used for the present analysis. England (1995) found that, for his coarseresolution global model, 4650 years of integration were necessary for the model to reach equilibrium. However, the abyssal waters of the ocean were of interest in that study. In this case, since the water mass of interest, the subtropical mode water, is a relatively shallow water mass and is expected to have a relatively short ventilation time scale, 120 years should be enough for this calculation to be meaningful. However, as every water mass inevitably mixes in some of the adjoining water masses and some of these adjoining waters have longer equilibration times, 

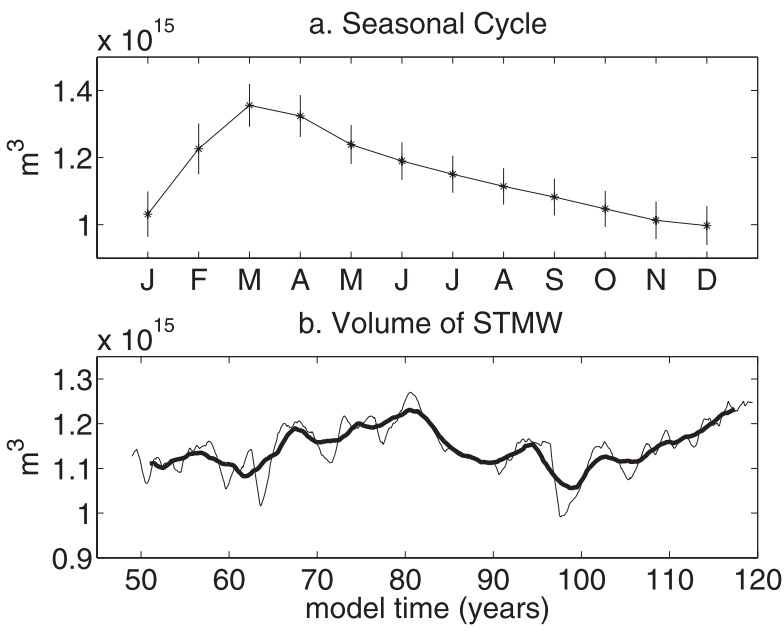

c. Path length south of Japan

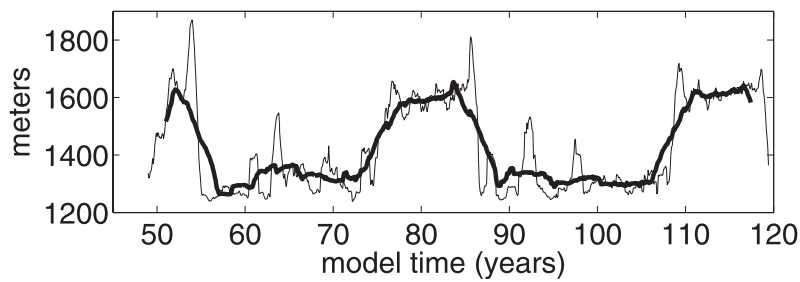

FIG. 2. (a) Seasonal cycle of the volume of STMW. Vertical lines represent \pm one standard deviation over a 70-yr mean. (b) Time series of the volume of STMW. (c) Variation of the pathlength south of Japan, indicative of the large meander. In (b) and (c) the thin line indicates 1-yr smoothing to remove the seasonal cycle and the thick line indicates 5 -yr smoothing.

there is still a long-term trend in the age of STMW. These trends are removed, and the variability that remains is used to analyze the model output.

Transit-time distributions are another tracer field used in the model. The concept here is similar to a dye experiment (England 1995; Peacock and Maltrud 2006). At the surface, the TTD is set to one, for the duration of one year. After this year, the surface value of TTD is set to zero. The tracer spreads through the model, like a dye, through advection and diffusion and thus presents a picture of where water goes after ventilation. A third tracer recorded by the model is CFC-11. The partial pressure of CFC-11 in a given water parcel preserves the atmospheric pressure of CFC-11 when the parcel was at the surface and can be used to determine how long it has been since that parcel was ventilated. Analyses of these tracer fields allow further understanding of ventilation time scales in the model.

\section{Subtropical mode water}

\section{a. Definition}

As mentioned previously, STMW is the deep winter mixed layer water that is subducted beneath a seasonally formed thermocline at the end of winter. It can be identified by a low gradient of temperature or potential density. It can also be described by a layer of low planetary potential vorticity, defined here as

$$
Q \equiv-\frac{f}{\rho} \frac{\partial \sigma_{\theta}}{\partial z} .
$$

In this analysis, several constraints were used to ensure that the water under analysis was really STMW. Following Rainville et al. (2007), STMW has $Q<2 \times 10^{-10} \mathrm{~m}^{-1} \mathrm{~s}^{-1}$, temperature between $16^{\circ}$ and $20^{\circ} \mathrm{C}$, and potential density between 25.0 and $25.5 \mathrm{~kg} \mathrm{~m}^{-3}$ (Masuzawa 1969; Hanawa and Suga 1995). Finally, the thickness of the layer of STMW must be greater than $50 \mathrm{~m}$, thus excluding thin surface mixed layers. This set of constraints ensures proper identification of the water mass.

\section{b. Volume}

The volume of total STMW is calculated for each month during the model run. Potential vorticity information for the model is only recorded during years 48 119 so that a 72 -yr period is considered.

Figure 2a shows the seasonal cycle of the volume of mode water. The seasonal cycle is strong with changes of $20 \%$ of the mean volume. The volume of mode water peaks in March each year when the winter mixed layer is at its deepest. STMW stays high in April and then slowly declines through the rest of the year, reaching a minimum in December. Some increase is seen in January and February as the mixed layer deepens to entrain older STMW, and the peak in STMW volume is reached again in March.

To highlight the interannual variability that exists over and above this intense seasonal cycle, a 12-month running mean is applied to the time series of STMW volume. A 60-month (5 yr) running mean is also calculated, highlighting the decadal time-scale features of variability. For the remainder of this analysis, the 1-yr and 5-yr smoothed time series will be used almost exclusively. These time series are shown in Fig. 2b. There is significant interannual variability in the volume of STMW over the full time period, with peak-to-trough changes of more than $10 \%$ of the total volume even after the seasonal cycle is removed.

A physical feature whose effect on STMW will be explored to some extent in this analysis is a large meander in the Kuroshio that appears south of Japan. This feature is not just a model artifact; it is comparable to a feature that has been observed (Kawabe 1995). The fact that it is well represented in the model indicates that it is intrinsic to the ocean, in agreement with previous research (Qiu and Miao 2000). Although a full discussion of 


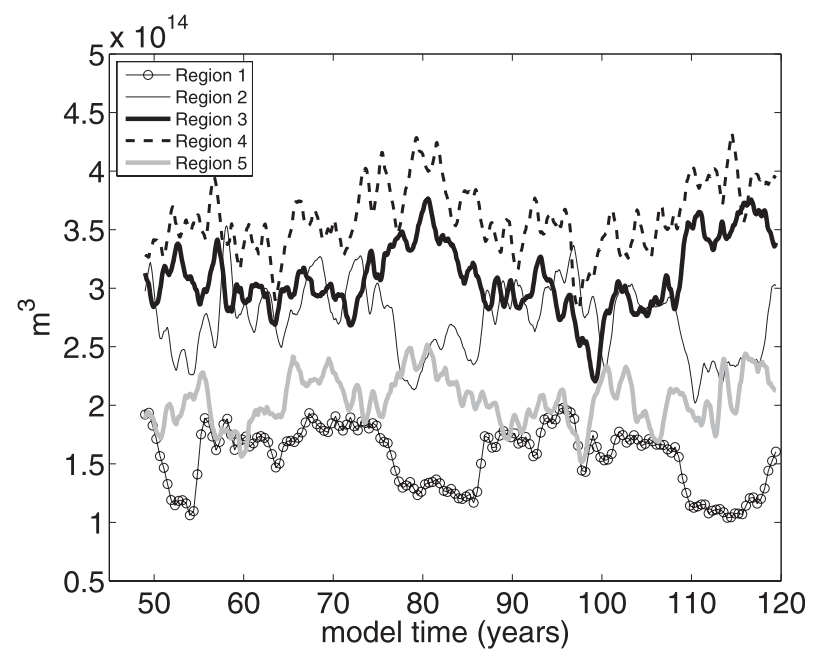

FIG. 3. Total volume of mode water in each of the geographical regions.

the feature is beyond the scope of this paper, its effect on STMW will be explored. As a measure of the presence of this feature, we use the pathlength of the Kuroshio south of Japan. When this pathlength is high, the Kuroshio is following its large meander path. This index is plotted in Fig. 2c. There is some correlation between the volume of STMW and the pathlength; when the Kuroshio is in its large meander state, the volume of STMW is higher. This connection will guide the regional analysis as the time variability of STMW is explored.

The region is divided into four sections and one subsection. The four sections divide up the Kuroshio and its extension zonally from the coast of Japan all the way to $180^{\circ}$; the subsection focuses on the region south of Japan where the large meander would be expected to have the most influence. All five areas are indicated in Fig. 1.

The volume of mode water in each of the five regions indicated in Fig. 1 is shown in Fig. 3. The previously noted strong seasonal cycle has been removed by using a 12 -month running mean. Region 1 , which focuses on the large meander region, and region 2 , which encompasses region 1, have several distinct drops in STMW volume. These coincide with the large meander state of the Kuroshio. This result is consistent with results in Suga et al. (1989), who observed less STMW along $137^{\circ} \mathrm{E}$ during the large meander in the 1970s. The other regions have slightly more mode water during the large meander, although the effect is not as dramatic. This connection with the large meander will be discussed below.

\section{c. Core properties}

The core properties of mode water are calculated at the depth in the water column where the temperature gradient is at a minimum. Core layer temperature (CLT) a. Core Temperature

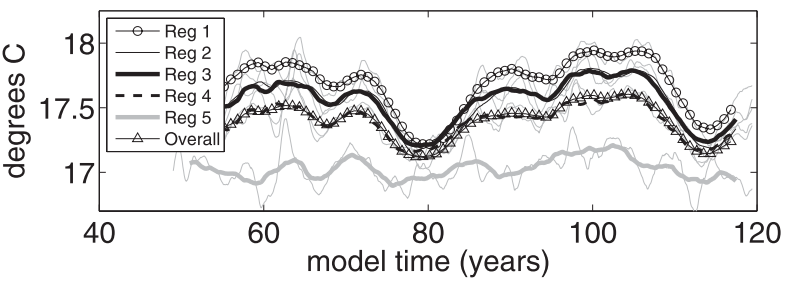

b. Core Depth

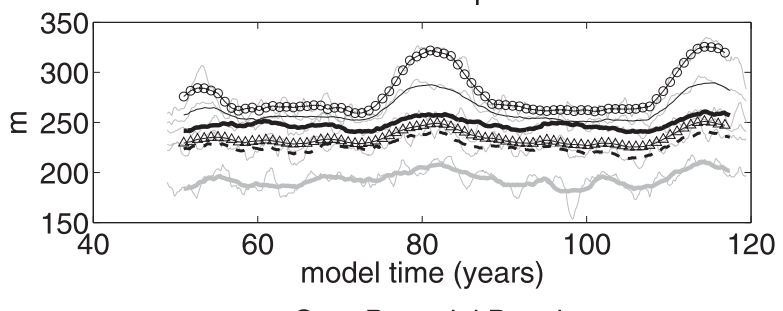

c. Core Potential Density

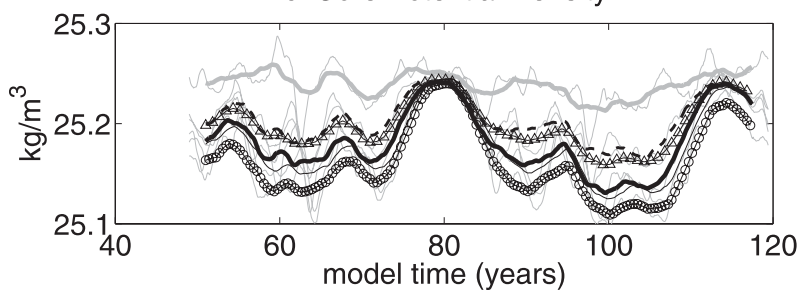

FIG. 4. Averaged core layer (a) temperature, (b) depth, and (c) potential density by region. Thin gray lines denote 1-yr smoothing; other lines denote 5-yr smoothing.

is one of the standards used in analysis of subtropical mode water (Hanawa and Kamada 2001). Variations in core layer temperature are evident in Fig. 4a. The changes in core layer temperature are anticorrelated with depth of the core (shown in Fig. 4b) as well as with density of the core (Fig. 4c). More importantly, changes in all of the core properties are consistent throughout all of the regions.

The signals diminish in strength from regions 1 to 5, or from west to east. For example, the decrease in temperature in region 5 in year 80 is not distinguished from the normal variability of the time series, while in region 1 the decrease in temperature in year 80 is nearly half a degree. However, the signal is coherent throughout the water mass. This makes sense, given that one would expect the water in the subtropical gyre to be coherent. Changes seem to be associated with the large meander; the changed pathway of the Kuroshio affects the water properties in the nearby recirculation gyre, with the most distinct changes in the closest water and the influence decreasing with distance.

There are differences between the regions. The STMW is warmer, deeper, and less dense in the west near Japan than in the east, in agreement with previous research (Suga and Hanawa 1990). The temperature and density differences are associated with the warmer sea surface 
a. Volume of mode water formation

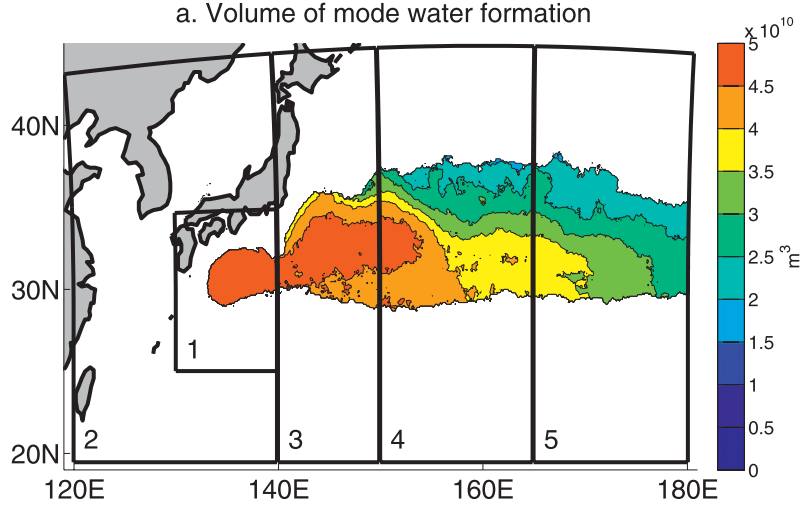

b. Mean thickness of mode water

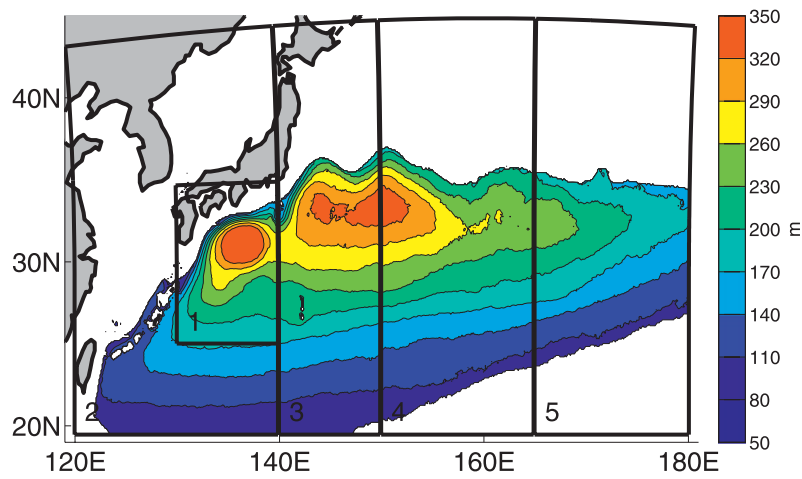

FIG. 5. Map of (a) the average formation and (b) average thickness of mode water. Locations where MW exists less than $25 \%$ of the time are masked.

temperatures and lower densities in the west during the formation time period. The depth of the core is associated with the thickness of the layer; a thicker thermostad of STMW is formed in the west, and the core of the layer is deeper. Both the decrease in core layer temperature from west to east and the correlation of CLT variability in different regions have been noted in previous research (Hanawa and Kamada 2001).

Previous studies have shown that the temperature of the mode water is highly correlated with the winter SST in the formation region (Hanawa and Kamada 2001). The same correlation is found in the present analysis. Following Hanawa and Kamada, time series were constructed of winter SST (February and March) in locations of mode water formation and of mean core layer temperature for May through December of a given year (not shown). Statistically significant correlations were found in regions 3,4 , and 5 with coefficients of $0.77,0.56$, and 0.60 , respectively. No statistically significant correlation was found between CLT in regions 1 and 2 and SST in those regions. As will be discussed below, very little mode water is formed in regions 1 and 2 , so the lack of a relationship is not surprising.

\section{d. Formation}

STMW is formed when winter winds create a deep mixed layer of water with uniform properties. The uniform water mass is later subducted, retaining these properties, when the seasonal thermocline forms in the spring. Figure 5a shows a map of formation volume, averaged over the full time series. In this analysis, formation volume is the volume of STMW in contact with the surface at any given time since the properties of the water mass are renewed whenever it is ventilated. To be considered newly formed mode water, the mode water layer must be in contact with the surface. It should be noted that this definition of "formation" will include mode water that is reventilated as a result of a thick mixed layer reaching the top of a previously formed thermostad of subtropical mode water. It could be argued that this overestimates formation, by including previously formed mode water, and that this is older mode water that is not actually ventilated. However, as there is no easy way to quantify where the ventilated part of the uniform layer ends, this imperfection is acknowledged but the metric is still used. Other methods of quantifying newly formed mode water, such as a lower limit on ideal age, gave similar results. As with all mode water, the layer must be more than $50 \mathrm{~m}$ thick. The map excludes locations where mode water was formed in fewer than $25 \%$ of years. As shown in the figure, formation regularly occurs just south of the Kuroshio Extension all the way to the date line, in agreement with previous research (Hanawa 1987; Hanawa and Kamada 2001). Most formation takes place between about $135^{\circ}$ and $155^{\circ} \mathrm{E}$, in regions 3 and 4 as drawn on the map.

\section{e. Thickness}

The thickness of mode water gives further information about its geographical distribution. The time-averaged thickness of the mode water layer is mapped in Fig. 5b. Mode water is seen to cover the full region, as far east as the date line and as far south as a latitude of $20^{\circ} \mathrm{N}$. By comparison with the map of formation in Fig. 5a, it is clear that STMW spreads southward and westward after subduction. The thickest layers of mode water are found in regions 1,3 , and 4 , where layers have an average thickness exceeding $300 \mathrm{~m}$. Thickness of the mode water has previously been found to be related to the depth of the main thermocline at locations of mode water formation (Uehara et al. 2003). Thermocline depth is defined here as the $12^{\circ} \mathrm{C}$ isotherm, following Uehara et al. (2003). Figure 6a shows an example temperature section across $33.4^{\circ} \mathrm{N}$ with the $12^{\circ} \mathrm{C}$ isotherm in bold, demonstrating that this metric is a reasonable indication of the depth of the permanent thermocline. There is a correlation 
a. Temperature, $33.4 \mathrm{~N}$, Dec. year 119 , with $12 \mathrm{C}$ contour
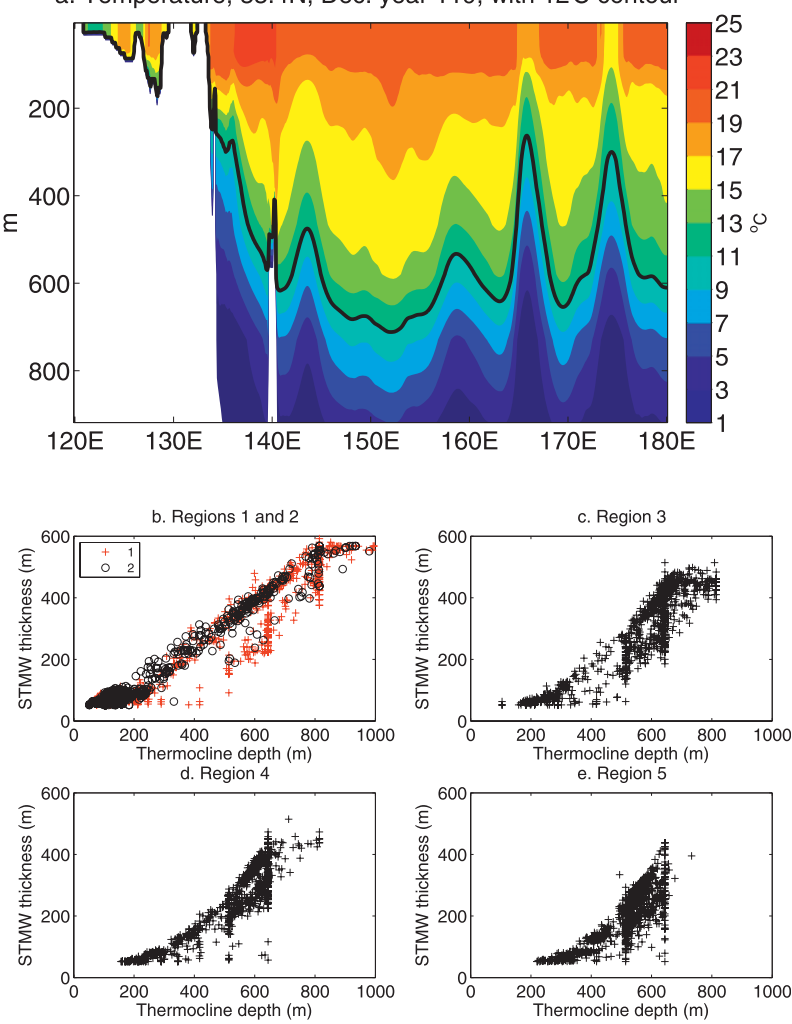

FIG. 6. (a) Sample temperature section, contour intervals $2^{\circ} \mathrm{C}$. The thick black line indicates $12^{\circ} \mathrm{C}$. (b)-(e) Mean STMW thickness vs thermocline depth at formation locations in each region.

between the thermocline depth and STMW thickness at locations where STMW is formed. Figures $6 \mathrm{~b}-\mathrm{e}$ show scatterplots of thickness of mode water as a function of thermocline depth in each of the five regions. On the plot, each plus sign indicates the spatially averaged STMW thickness and thermocline depth over all locations where STMW is formed during a given month. A "formation location" is one at which the STMW layer is in contact with the surface (being ventilated). Since thicknesses in this plot are shown for individual months rather than averaged, it becomes clear that the thickness of STMW can be much higher than the average thicknesses shown in Fig. 5b. Figures 6b-e show that, although the same association of deeper thermocline with thicker STMW is found in all five regions, the slopes differ. All are plotted on the same size axes for ease of comparison. In regions 1 and 2, at the western edge of the basin, STMW thickness ranges from a maximum of $600 \mathrm{~m}$ at more than 1000-m thermocline depth down to $50 \mathrm{~m}$. Extremely high average thermocline depths indicate that mode water formation occurred in very limited regions of deep mixed layer at that time. All regions show similar relationships between thermocline depth and layer thickness, but in

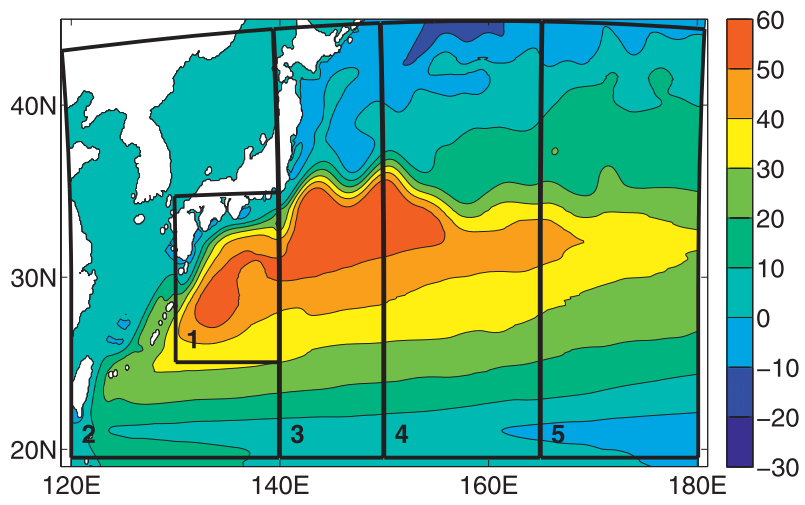

FIG. 7. Transport streamfunction (Sv) vertically averaged from 50 to $600 \mathrm{~m}$, contour intervals $10 \mathrm{~Sv}\left(\mathrm{~Sv} \equiv 10^{6} \mathrm{~m}^{3} \mathrm{~s}^{-1}\right)$.

more easterly regions the ranges of both STMW thickness and thermocline depth are limited. There is also more scatter in the east; in region 5 there are locations with thermocline depth of more than $600 \mathrm{~m}$ where STMW thickness is only $50 \mathrm{~m}$, which does not happen in regions 1,2 , or 3 .

\section{f. Transport streamfunction}

To examine the advection of STMW, a transport streamfunction can be calculated using the velocity fields of the model. The streamfunction $\psi$ of the transport with zonal component $U$ and meridional component $V$ is calculated using the definition

$$
\begin{aligned}
U & =\iint u d y d z, \\
V & =\iint v d x d z, \\
d \psi & \equiv U d y=-V d x,
\end{aligned}
$$

and

$$
\psi \equiv \int U d y=-\int V d x,
$$

where $\psi$ is defined to be zero at the coastline. The longterm means of the zonal and meridional components of velocity are used in this calculation. The resulting streamfunction, averaged at depths from 50 to $600 \mathrm{~m}$, is shown in Fig. 7. The depth range is chosen because most STMW lies within these approximate limits; the core depth, as shown in Fig. 4b, averages between 200 and $400 \mathrm{~m}$ in all five regions. The transport streamfunction shows the expected figure of the subtropical gyre, south of the Kuroshio Extension. Comparing this with the map of formation shown in Fig. 5a, it appears that STMW formed in the east, in regions 4 and 5 in particular, would 
a. Age of mode water

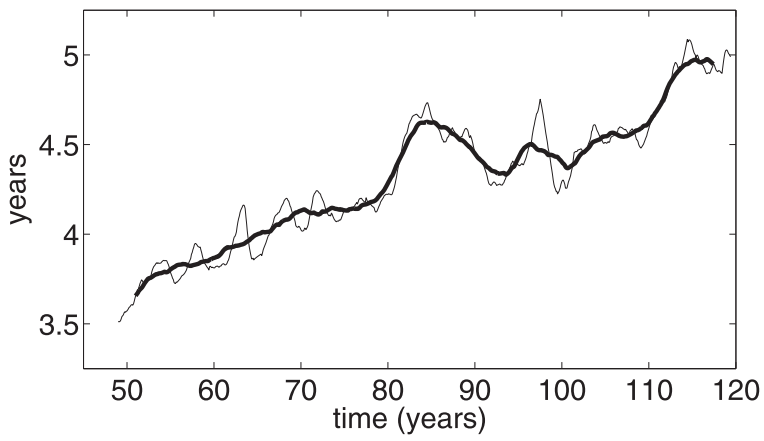

b. Distribution of mode water (12-month smoothing applied)

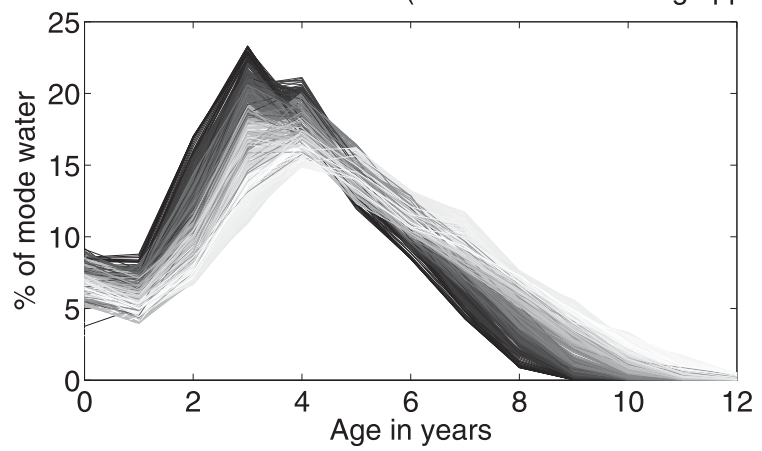

FIG. 8. (a) Age of STMW, smoothed over one year (thin line) and five years (thick line). (b) Age distribution of all STMW after oneyear smoothing: black denotes the oldest profiles (year 48), and white denotes the newest profiles (year 120). Bins are one year in width.

travel along streamlines toward regions 2 and 3, leading to a pattern of thickness (Fig. 5b) that looks nearly identical to the streamfunction itself. From the streamfunction, it is possible to determine that the average travel time for a parcel along a streamline from region 5 to region 2 is approximately $2.5 \mathrm{yr}$.

\section{Time scales}

The previous section dealt with the physical characteristics of mode water. The present section will use several tracers to identify the time scales of the life cycle of mode water.

\section{a. Ideal age}

Ideal age, as described above, is a tracer that gives the amount of time since a given parcel of water was last ventilated. There are several useful quantities that can be determined from ideal age. First, there is the mean age of the mode water, shown in Fig. 8a. As noted previously, there is an increasing trend, which will be removed for the purpose of understanding the variability. After smoothing to remove the annual cycle, there is still significant variability evident in the results.
The distribution of ages of mode water, shown in Fig. $8 \mathrm{~b}$, is helpful in understanding the long-term trend in age. For each year, the total volume of mode water is binned by age. The volume in each bin is then divided by total volume to give the percentage of mode water. The first bin (bin 0) shows the percentage of water with age between 0 and $0.5 \mathrm{yr}$, and above that bins have a width of one year (0.5-1.5 yr, 1.5-2.5, etc.). The color represents the time: black is the first year and white is the final one. As the years progress from black to white, there is a shift from a sharp peak centered on 3 , indicating that $30 \%$ of mode water is between 2.5 and $3.5 \mathrm{yr}$ old, to a softer peak spread between 3 and 4 . As the peak shifts, the tail of the distribution also drifts to indicate more water in older bins. At the end, the distribution shows far less water in the 2-yr-old range and considerably more water with ages reaching $10 \mathrm{yr}$ old. This progression is another illustration of the trend in Fig. 8a, indicating the increase in mean age with time. Despite this trend, the basic structure of the distribution is quite robust and the plurality of the mode water is between 3 and $5 \mathrm{yr}$ old. This is a much longer time scale than data have indicated; for example, Suga et al. (1989), using apparent oxygen utilization rates, found no trace of mode water as old as 2 yr. However, it is similar to the 2.5-yr transit time implied by the streamfunction. Warner et al. (1996) used estimates from CFCs to find an upper limit of $2-5 \mathrm{yr}$ on the age of STMW. A logical question to ask is whether mixing with surrounding waters, which might have older ages than the mode water itself, would give mode water an average age that is higher than the actual amount of time since subduction. The long-term trend in mode water ages, discussed previously, indicates that the aging of surrounding waters and mixing with those waters is an important process. Thus, the ages calculated here are most likely an upper limit rather than a welldefined mean.

Since one would expect these effects to be similar in all regions, analysis of relative differences between regions is still valid. The mean age distribution is determined for each of the geographical regions described above. These distributions are shown in two different ways in Fig. 9. Figure 9a is the absolute volume in each age bin, averaged over the full time series. In this figure, the total area underneath the curve is equal to the average volume of mode water in the associated region. Regions 3 and 4 have the most STMW, in agreement with Fig. 3. The far left of the distribution indicates the volume of mode water with age between 0 and $0.5 \mathrm{yr}$. This is the amount of newly formed mode water in each region. Regions 4 and 5 have the most newly formed mode water, followed by region 3 . This geographical pattern is supported by previous research, which has identified 


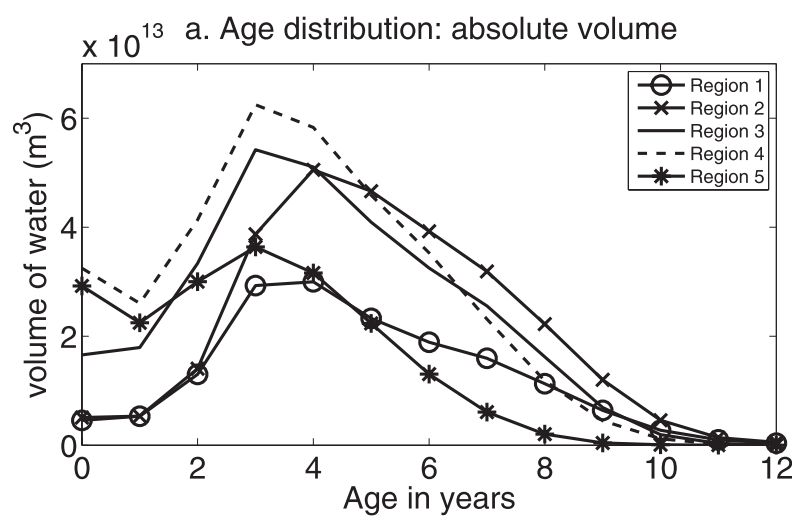

b. Age distribution: percentage volume

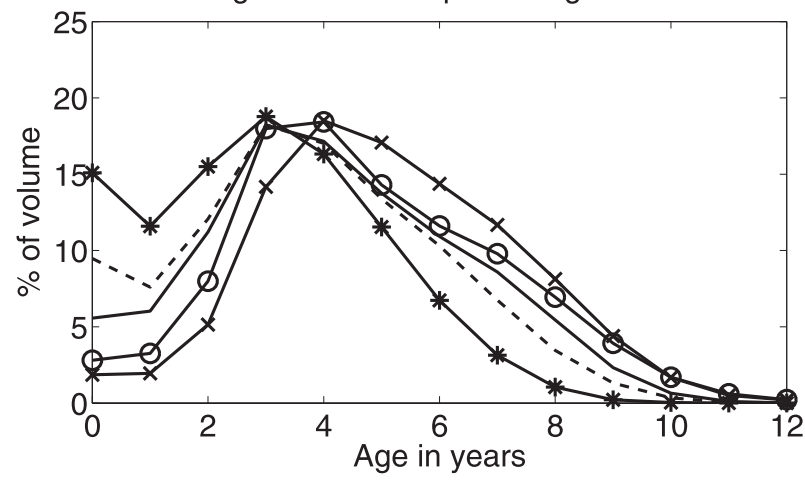

FIG. 9. Distributions of mode water ages in different regions: (a) total and (b) percentage of mode water.

the main formation region for mode water as the eastern Kuroshio Extension region, just south of the main jet (Suga et al. 1997). Figure 9b shows the same distributions, normalized by volume. As the regions progress from east (region 5) to west (regions 1 and 2), the distribution shifts from younger to older. This gives some indication of the life cycle of mode water. Formation occurs in the easternmost regions, where the highest percentage of total mode water is newly formed. Mode water then drifts westward with the mean circulation, aging as it progresses such that the westernmost mode water is the oldest. The average age of mode water in region 5 is $3.0 \mathrm{yr}$, whereas that in region 2 is $5.2 \mathrm{yr}$.

A map of the vertically averaged mean age of mode water reinforces the impression that mode water is formed in the eastern region of the Kuroshio Extension and then moves westward with the large-scale gyre circulation (Fig. 10). When averaged over the full time series, STMW in the east has an age of $2 \mathrm{yr}$ or less. The mean age progressively increases from northeast to southwest. While formation occurs in all regions, the advection from the east of older mode water leads to a higher average age. The age gradient is not extremely steep, but it is well defined in the mapped age.

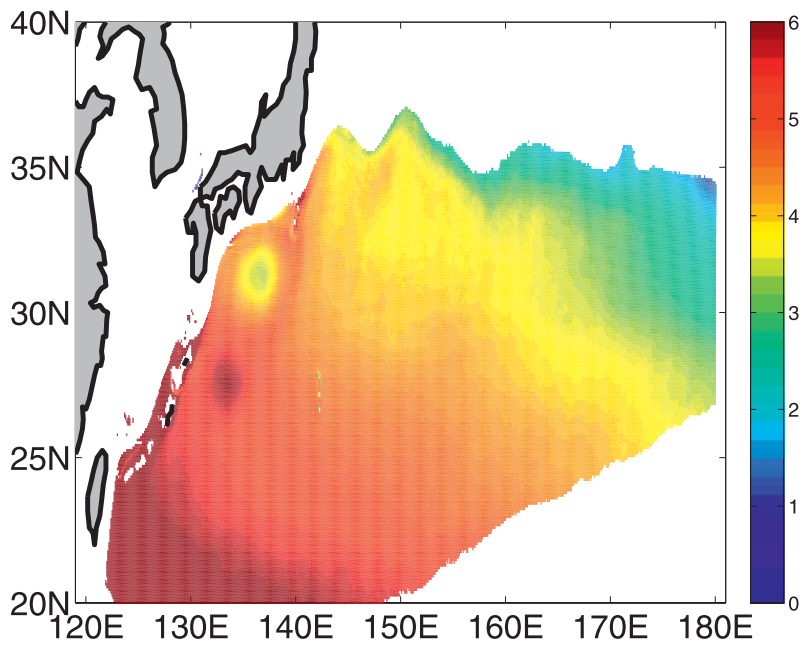

FIG. 10. Map of mean age of mode water. Units are years. Values are shown only at locations where mode water exists at least $25 \%$ of the time.

The time variability of age in each of these regions is also of interest. Figure 11a shows the time series of average age of STMW in each of the five geographical regions. This demonstrates again the progression of mean age from youngest in the east to oldest in the west. Correlations are calculated between the overall average age of mode water and the average age of mode water in each region. The time series are detrended prior to the calculation because, although the trend is a real effect, leaving it in before the calculation artificially increases the correlation. While there is some correlation between average age in each of the five regions with the overall age of mode water, region 4 has the highest correlation by far at 0.82 , with the other four regions all having correlations close to 0.60 . As was noted previously, region 4 has a large volume of newly formed water; in fact, more mode water is formed in region 4 than in any of the other regions (see Fig. 9). The high correlation between the age of water in region 4 and the total age of mode water indicates that variability in formation of new mode water, rather than changes in erosion rates, is the dominant factor in controlling the average age of the water mass.

\section{b. Core age}

In the same way as the average age, the core age shows a secular increase in time (Fig. 12). The behavior of the core age is very similar to the core temperature and core depth and, in fact, correlations between these variables are very high. The most obvious signal is a distinct increase in age, coincident with the large meander feature mentioned previously. The distinct signal of increased age during large meanders is most obvious in region 1 , but increases in age occur in the cores of all regions, as 
a. Average age smoothed over 1 year

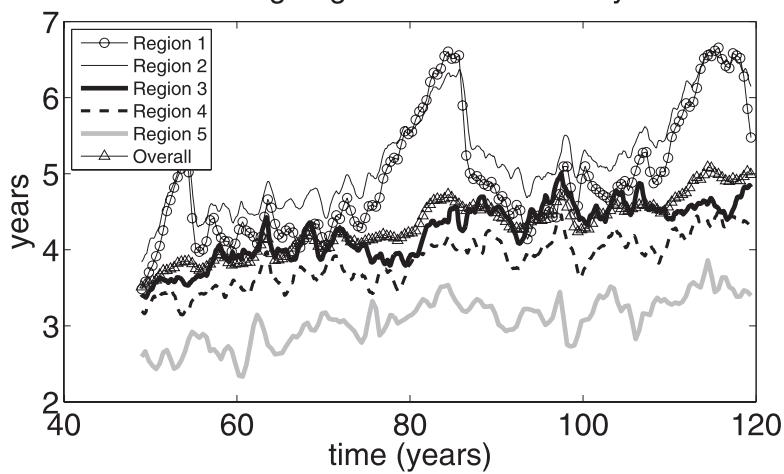

b. Detrended average age smoothed over 1 year

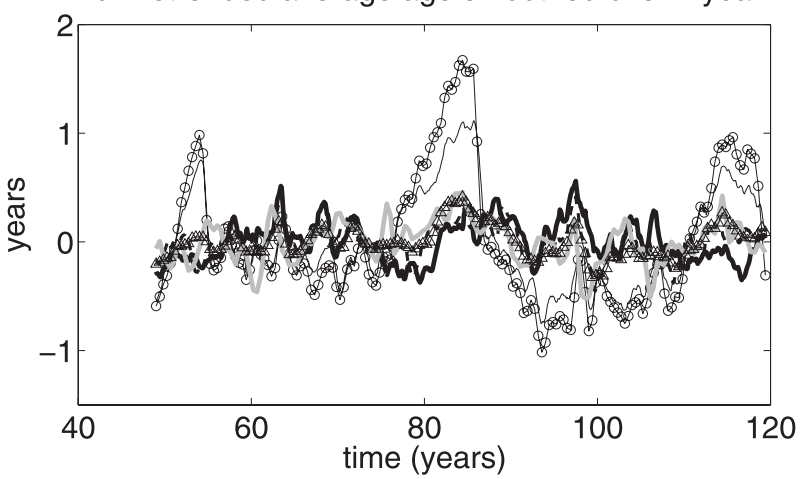

FIG. 11. (a) Average age in each geographical region, detrended in (b) to highlight nonsecular variability.

well as in the overall core age. The mechanism through which the large meander affects the rest of the STMW will be discussed below.

\section{c. $C F C s$}

Although ideal age is a useful model metric, it is not something that can be measured or calculated in a real physical ocean. However, chlorflourocarbons can be used to approximate the time since a water parcel was ventilated. Although the physical state of the modeled atmosphere does not change from year to year, the atmospheric concentration of CFC-11 was allowed to evolve, from years 48 to 72 , according to atmospheric CFC-11 concentrations from 1983 to 2007. Age can then be calculated from the partial pressure of CFC in water. Following Doney and Bullister (1992), the partial pressure of CFC-11 in a given water parcel is assumed to be equal to the atmospheric concentration of CFC- 11 when that parcel was subducted (see Fig. 13a for an example). Ages found in this way are shown in Fig. 13b for years 49-59. After model year 57, the ages are increasing in a nonphysical way, associated with the reduction in slope and eventual decrease in atmospheric CFC concentration. As a result, this method can only be used to analyze the age of mode water through the first eight years of model a. Core Age

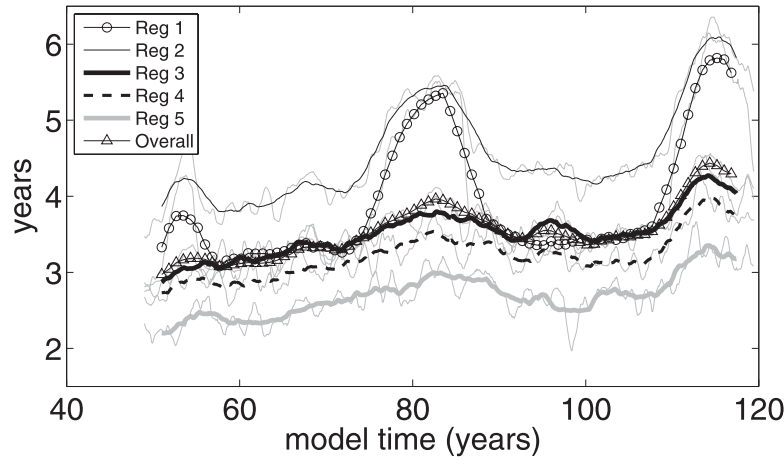

b. Core Age, Detrended

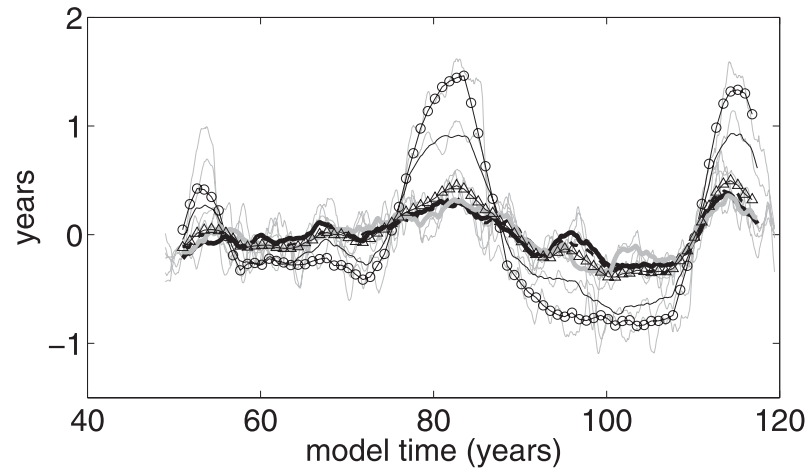

FIG. 12. (a) Age of the STMW core in each region along with average age for the full area of study; (b) as in (a) but with a linear trend removed from each time series. In (b) the mean for each time series is as in (a). Thin gray lines denote 1-yr smoothing, and other lines denote 5-yr smoothing.

CFC output (49-56). During that time, however, average ages for mode water in regions $1-5$ are $4.3,4.4,3.4$, 3.2 , and $2.3 \mathrm{yr}$ respectively, in qualitative agreement with the average ages stated previously. These averages also agree with mode water age estimates of 2-5 yr from observed CFCs (Warner et al. 1996). Additionally, the time series shows an increase in age in regions 1 and 2 between years 51 and 54 during the associated large meander, in agreement with the feature noted in the ideal age estimates.

\section{d. Transit-time distributions}

As mentioned previously, TTDs are used in this experiment to observe the distribution of recently ventilated water. The TTD field is set to one at the surface of the model every time step for a year, after which it is set to zero at the surface. The quantity propagates as a passive tracer through advection and diffusion. Quantitatively, the magnitude of TTD of a water parcel represents the probability that the parcel was at the surface during the time of tracer release. In this case, the tracer release took place during year 51. For years 51-56, maps 

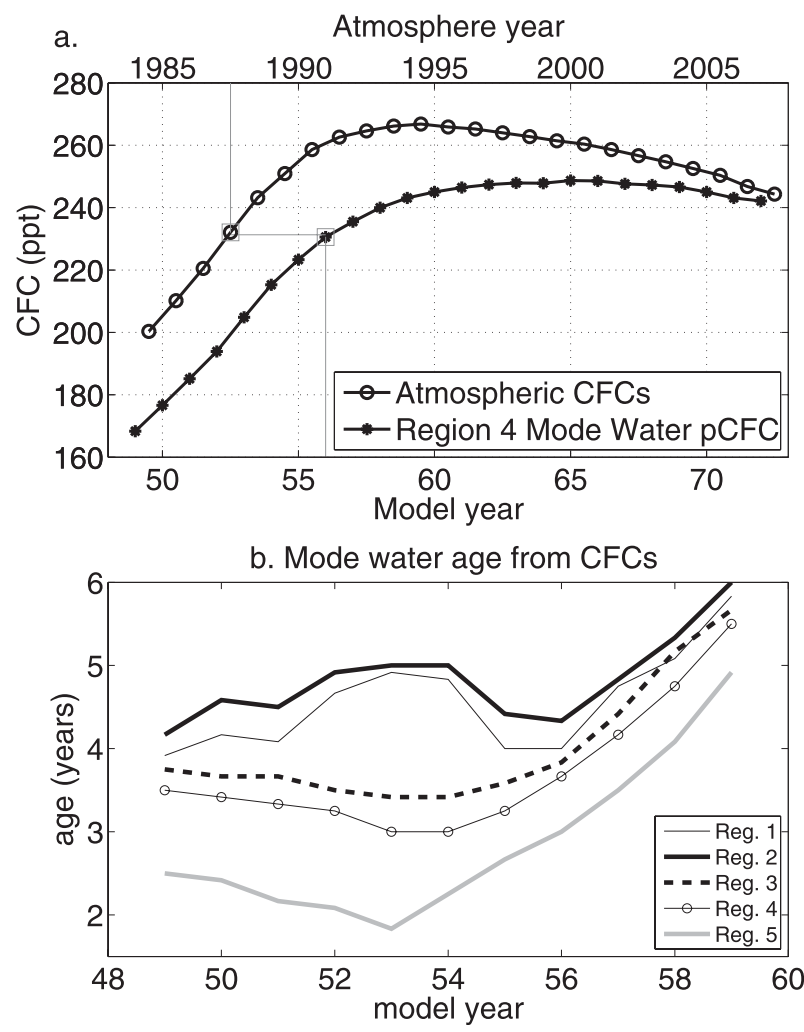

FIG. 13. (a) As an example, atmospheric CFC and $p$ CFC in the mode water in region 4 . Average $p C F C$ in year 56 is equivalent to atmospheric CFC 3.5 years prior, in atmospheric year 1987.5 (model year 52.5). Thus, the average age of region-4 mode water in model year 56 is 3.5 yr. (b) Average ages of mode water for all five regions from CFCs, for the first 11 years.

of the vertical integral of tracer within the mode water are shown in Figs. 14a-f. For each year, the base-10 logarithm of the one-year average is displayed. All plots are shown using the same color bar, which shows the orderof-magnitude changes in total tracer volume. While TTD is conserved globally, it is mixed out of the mode water quickly so that total TTD in the mode water decreases exponentially in the six years shown here. In the year of tracer release, concentrations are high south of the Kuroshio Extension from its separation point all the way to $180^{\circ}$ (Fig. 14a). The following year, the high concentrations of the tracer are still found throughout the ba$\sin$, although the magnitudes in the farthest east regions begin to decline as the mode water formed in those regions is advected westward (Fig. 14b). Throughout the next $4 \mathrm{yr}$, the westward migration continues. Since this figure shows annual averages, the effects of the seasonal cycle are not evident. By year 56, the amount of tracer is two orders of magnitude lower than it was at the time of release, and the highest remaining concentrations are directly south of Japan. Concentrations where the STMW
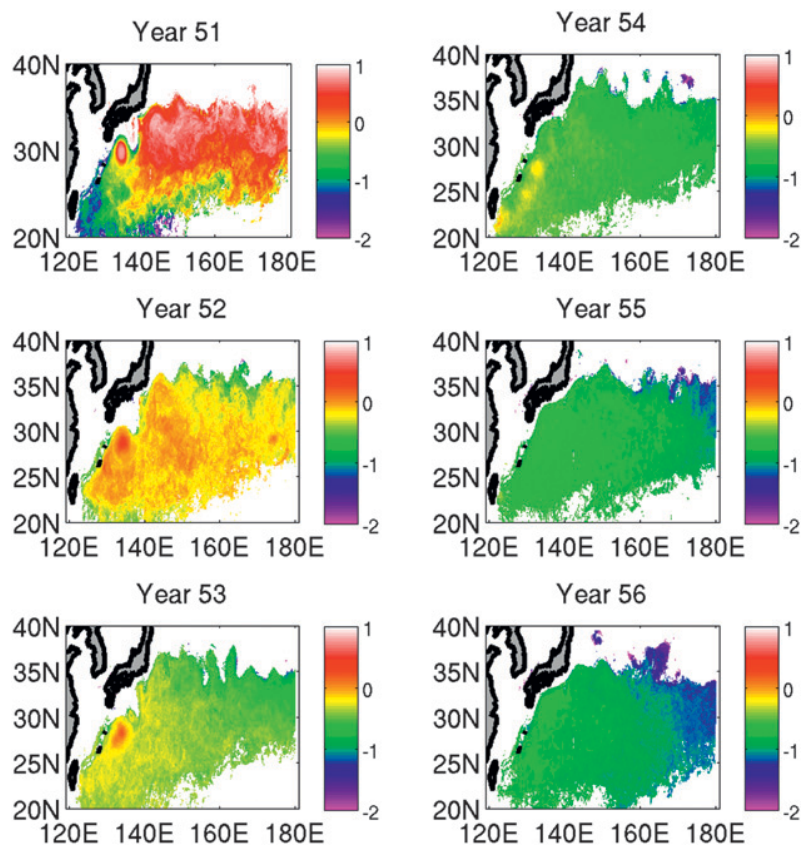

FIG. 14. Evolution of the tracer distribution, from release through the following five years. For each year, the mean of the vertical integral of TTD was calculated. The base-10 logarithm of the integral of the concentration is shown, emphasizing the order of magnitude changes taking place. In each year, locations where mode water existed for fewer than 3 of the 12 months are masked.

is the thickest on average (recall Fig. 5b) have been reduced by two orders of magnitude, but concentrations in the eastern regions where STMW is advected away the fastest have been reduced by nearly three orders of magnitude.

\section{Variability \\ a. Formation}

The amount of mode water formed in each of the regions is shown in Fig. 15a. As noted previously, formation volume is defined as the volume of mode water in contact with the surface. For each time series in Fig. 15, the average of February and March values define the quantity for a given year. These months are chosen because on average, as shown in Fig. 2a, February and March are the months of high formation, in which the volume of mode water exceeds the volume of mode water in the previous month. These are the months in which the mixed layer is maximum, at the end of winter, before spring restratification begins. The choice of months is slightly earlier than that used by Rainville et al. (2007) in their analysis of mode water formation; mode water volume in that analysis peaked in April. As indicated previously by the average age distribution (Fig. 9a), more 


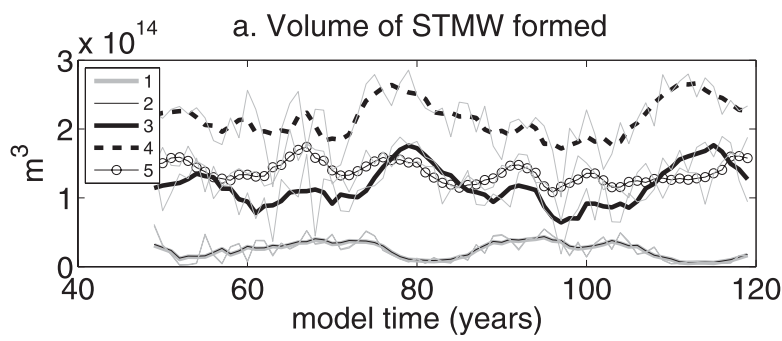

b. MLD at formation locations
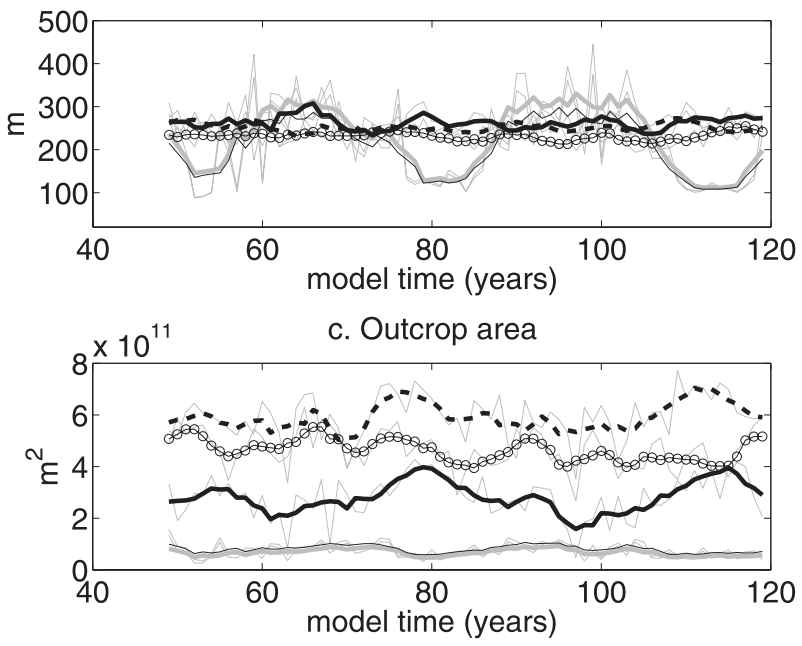

FIG. 15. (a) Average of February-March (a) volume of STMW formation $\left(\mathrm{m}^{3}\right)$, (b) MLD at formation locations (m), and (c) outcrop area $\left(\mathrm{m}^{2}\right)$. Different line styles denote different regions, as listed in the legend in (a). For all plots, formation occurs when the mode water layer is in contact with the surface.

mode water is formed in region 4 than in any of the other regions, followed by regions 5 and 3. Mode water formation is smallest in regions 1 and 2 , throughout the time series. The lines for regions 1 and 2 are nearly indistinguishable in Fig. 15a because all mode water formed in region 2 is formed within the confines of its subregion, region 1. During large meander events, mode water formation in regions 1 and 2 is suppressed even more. In regions 3 and 4, formation increases during large meander events. The details of the impact of the large meander will be discussed later in the analysis. In addition to having the largest mode water formation, regions 3 and 4 also have the most variability in formation with standard deviation $2.8 \times 10^{13} \mathrm{~m}^{3}$ and $2.6 \times 10^{13} \mathrm{~m}^{3}$, respectively. Variability in regions 1,2 , and 5 are all smaller, with standard deviation $1.1 \times 10^{13} \mathrm{~m}^{3}, 1.1 \times 10^{13} \mathrm{~m}^{3}$, and $1.5 \times$ $10^{13} \mathrm{~m}^{3}$, respectively.

\section{b. Causes}

Several factors could affect with variability of STMW formation. In nature, one possible source of variability is atmospheric forcing, but, in this model, the atmospheric
TABLE 1. Correlation coefficients between the formation of mode water and the surface area of formation and the mixed layer depth in each region.

\begin{tabular}{ccc}
\hline \hline Region & Mixed layer depth & Surface area \\
\hline 1 & 0.77 & 0.89 \\
2 & 0.80 & 0.89 \\
3 & 0.38 & 0.97 \\
4 & 0.31 & 0.92 \\
5 & 0.49 & 0.90 \\
\hline
\end{tabular}

state is prescribed to be the same in each year, with the exception of the feedback into heat flux from SST (which, as noted, is small). Because mode water is formed by the creation of a mixed layer, the depth of that layer could be the determining factor in the volume of mode water formed (Suga and Hanawa 1990). On the other hand, the outcrop area of the water mass could also have a significant effect: more surface area of formation would lead to greater total formation. Mixed layer depth and outcrop area in each of the regions are plotted in Figs. 15b and $15 \mathrm{c}$. As before, a model grid point is defined as part of the formation region if the mode water layer is in contact with the surface. It is evident that the average mixed layer depth in the region of formation does not change very much throughout the time series in regions 3,4 , and 5 but that the outcrop area of the water mass changes significantly. Correlations can be calculated in each region between the amount of mode water formed and the mixed layer depth and the outcrop area. These are listed in Table 1. Although regions 1 and 2 show high correlations with both surface area and mixed layer depth, regions 3,4 , and 5 show strong correlations with surface area but much weaker relationships with mixed layer depth. Because regions 3, 4, and 5 represent the regions where most mode water formation occurs, it seems that the critical factor in determining how much mode water is formed is the outcrop area rather than the mixed layer depth.

\section{c. Large meander effects}

At this point, some analysis of the specific effects of the large meander on mode water and its formation are warranted. A correlation exists between the total volume of mode water and the existence of this meander south of Japan in the pathway of the Kuroshio. Formation of mode water decreases in regions 1 and 2 , while increasing in regions 3 and 4. Correlated signals are also evident in the core properties of the mode water, including temperature, density, depth, and age. The mechanism through which a change in the pathway of the western boundary current could affect properties of a widespread water mass such as STMW deserves some attention. 
a. STMW formation during large meander

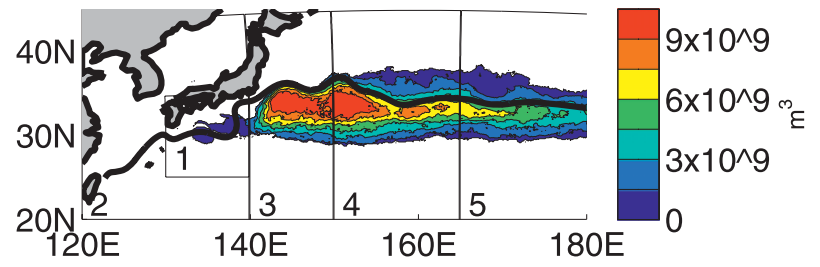

b. STMW formation, no large meander

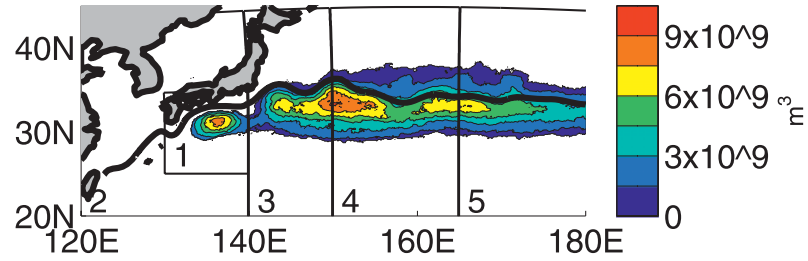

c. STMW thickness during large meander

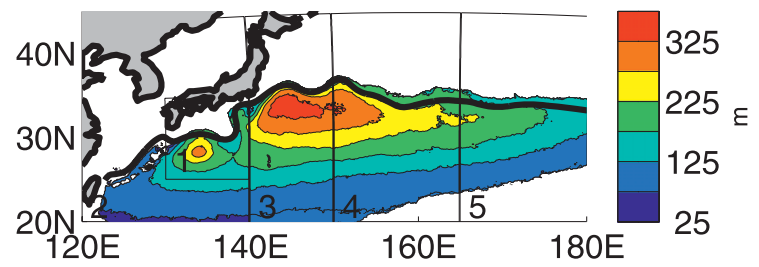

d. STMW thickness, no large meander

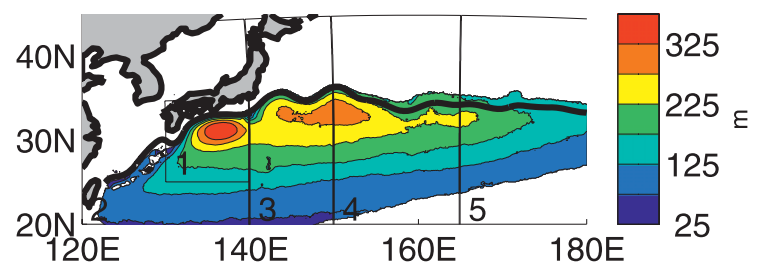

FIG. 16. Comparison of STMW formation during (a) large meander and (b) nonlarge meander periods. (c),(d) As in (a),(b) but for thickness.

Understanding the effect of the large meander on mode water formation is the key. Figures 16a and 16b show maps of the formation of mode water, averaged over all "large meander years" and all "nonlarge meander years." The average pathway of the Kuroshio in each state is shown as well, for reference. The average pathway of the Kuroshio is defined here as the SSH contour at $75 \mathrm{~cm}$. In region 1 , nearly no mode water is formed in large meander years, but there is significant formation in this region when the large meander is not present. In contrast, in regions 3 and 4, during large meander years, formation increases significantly in the recirculation gyre located just south of the semipermanent meanders of the Kuroshio Extension. The overall increase in mode water volume during these years is associated with the increase in mode water formation. The average thickness of STMW in each region is shown in Figs. 16c and 16d. In large meander years, the thickest mode water is in region 3 but, when the large meander breaks down, the thickest layer of mode water is in region 1 . Region 4 has more formation during the large meander, but the thickness of the mode water layer does not change much, on average. Region 5, situated the farthest from the phenomenon, is largely unaffected in both formation and thickness.

The connection between formation of mode water in the recirculation gyre and the pathway of the Kuroshio in the west can be found in the potential vorticity. When the Kuroshio is in its nonlarge meander years, anomalously low potential vorticity is stored in the region just south of Japan (region 1 in this analysis). This is reflected in high formation in this region when the large meander is absent. When the large meander forms, the low potential vorticity anomalies are exported eastward to the recirculation gyre (Qiu and Miao 2000). Formation just south of Japan is almost completely eliminated, but the total volume of mode water formed increases, as shown in Fig. 15a. With this decrease of potential vorticity, more water now fits within the low-PV criteria of mode water. Certain aspects of this relationship can be verified. Figure 16b shows significant mode water formation south of Japan, when no large meander in the Kuroshio pathway exists. A spatial average of potential vorticity over the top $1500 \mathrm{~m}$ of region 1 is highly correlated with the large meander index $(r=0.81)$. This positive correlation indicates that, when there is no large meander, PV is low south of Japan. The potential vorticity in this region is also strongly anticorrelated with mode water volume $(r=-0.84)$; the potential vorticity increases when the large meander forms, and the mode water in that region breaks down.

In Fig. 16, the most significant difference in mode water formation occurs in region 3 where formation increases significantly during large meander years. A spatial average of potential vorticity in the part of region 3 where formation is occurring $\left(28^{\circ}-37^{\circ} \mathrm{N}, 140^{\circ}-150^{\circ} \mathrm{E}\right)$ is statistically anticorrelated with the large meander index $(r=-0.46)$, indicating that, when there is a large meander, PV decreases. As a result, formation increases, and total mode water increases. The signal in region 3 is statistically significant but small in magnitude. There is no statistical correlation between the potential vorticity in regions 4 or 5 and the pathlength. In region 4 , the increase in formation is not as intense as in region 3 and only affects half of the width of the region; this signal, averaged over the region, is not strong enough to be statistically significant. Region 5 is too far east to be strongly affected by the large meander.

Figure 17 shows the time series of potential vorticity in regions 1 and 3, along with the large meander index (repeated from Fig. 2). The periods identified as large meander events are shaded in this plot to make it easier to 

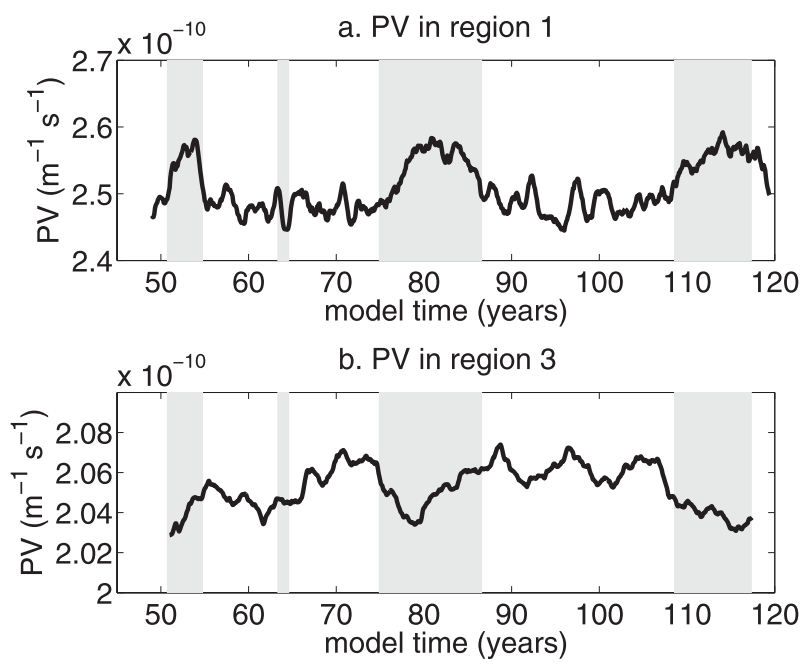

c. Large Meander Index

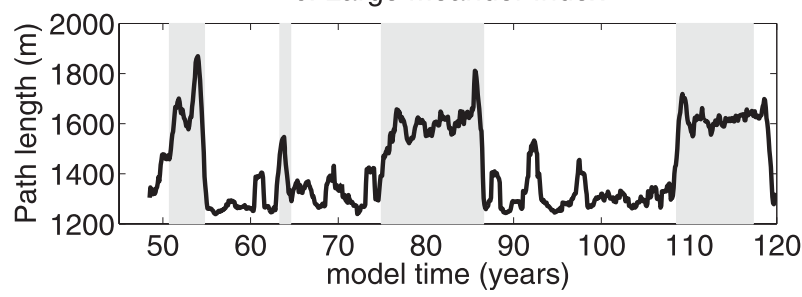

FIG. 17. (a) Average potential vorticity (a) in regions 1 and 2 and (b) in regions 3 and 4: (c) large meander time series for reference. In (a)-(c) large meander events are shaded for clarity.

compare variability between panels. Although the signals in region 3 are considerably weaker than region 1 , the overall effect of the large meander on the spatial distribution of the potential vorticity is clear. This is also reflected in changes in core properties of STMW throughout the subtropical gyre. Throughout the recirculation gyre, the core properties of STMW are affected by the large meander. In all regions, the potential vorticity of the mode water is reduced when the large meander forms. With more low PV, the mode water extends more deeply into the water column, so the layer is thicker and its core deeper and therefore colder, denser, and older. Additionally, although much of the mode water in region 1 is destroyed when the Kuroshio switches to the large meander pathway, the small volume that remains, south of the meander as evident in Fig. 16c, is blocked from being ventilated in the winter. This mode water is sequestered from the surface, and age increases significantly, leading to the abrupt increases in age shown in Fig. 11. Through these processes, a change of the path of the Kuroshio affects the full STMW water mass. The question of why the Kuroshio path changes into and out of the large meander state is more complicated. A more complete analysis of the details of the Kuroshio and its large meander is beyond the scope of

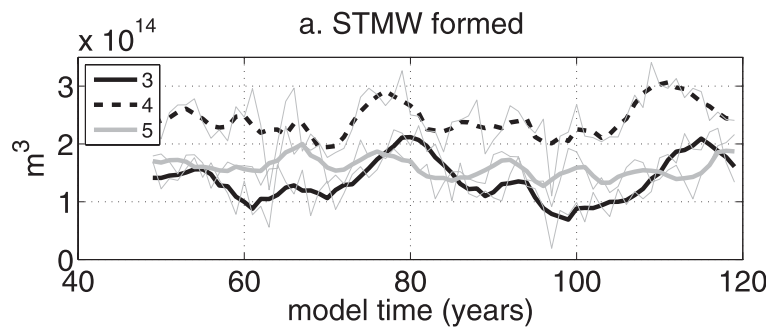

b. Latitude of Kuroshio

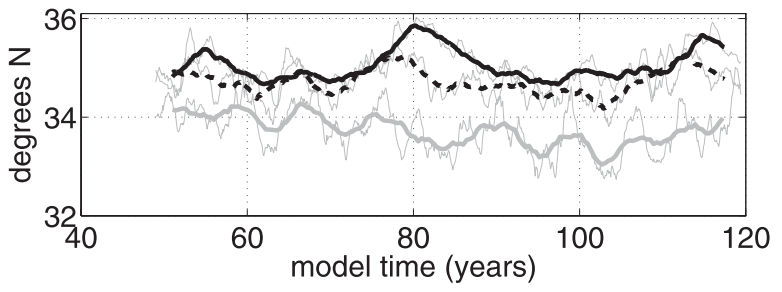

c. EKE

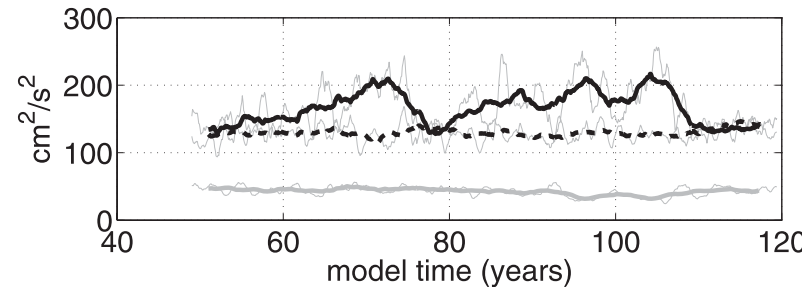

FIG. 18. (a) Average February-March STMW formation in regions 3-5, (b) average latitude of Kuroshio in regions 3-5, and (c) average EKE in regions 3-5. In all panels thin (thick) lines indicate 1-yr (5-yr) smoothing.

this paper but will be discussed in an upcoming manuscript.

\section{d. Dynamics}

Returning to the previous discussion, it was determined that the outcrop area of the STMW water mass is dominant in determining the volume of STMW formed. Following that train of thought, the dynamics affecting the outcrop area are explored. Since mode water forms south of the Kuroshio, it is possible that changes in the location of the Kuroshio itself are responsible for increases or reductions in the surface area available for mode water ventilation and formation. The average latitude of the Kuroshio is calculated for regions 3, 4, and 5, which are all east of the separation of the Kuroshio from the coast. In each of the three regions, there is a correlation between the latitude of the Kuroshio after separation and the surface area of formation. When the quantities are smoothed over one year, the correlations are $0.65,0.56$, and 0.60 for regions 3, 4, and 5 respectively. When the smoothing is over five years, correlations are even higher at $0.83,0.69$, and 0.69 for regions 3,4 , and 5 , respectively. This smoothed time series of latitude in each region is shown in Fig. 18b. Clearly, the meandering of the Kuroshio 
extension has a significant effect on the outcrop area of the water mass and, thus, on the volume of mode water formed in any given year.

Previous research has found an association between higher eddy kinetic energy (EKE) and the formation of more mode water in this region (Uehara et al. 2003). Thus, the area-averaged EKE in the top $600 \mathrm{~m}$ of the water column was calculated in each of the regions as well. EKE is calculated relative to monthly mean velocities, and results are smoothed over 60 months to eliminate highfrequency variability.

In this analysis, the connections with EKE are unclear. In region 3, there is anticorrelation between EKE and mode water formation with a correlation of -0.67 , implying that more mode water is formed when there are fewer eddies. In regions 4 and 5, on the other hand, there are positive correlations with mode water formation of 0.58 and 0.62 , respectively. However, variability of EKE in regions 4 and 5 is an order of magnitude smaller than that in region 3 (Fig. 18c). Overall, if there is a cause-and-effect relationship between eddies and mode water formation, it is not clear from this analysis.

\section{Discussion}

This analysis provides us with a picture of the formation and circulation of STMW in the North Pacific, as well as the variability of those processes. Mode water formation takes place south of the Kuroshio Extension. On average, more than $40 \%$ of all new mode water is formed between longitudes $150^{\circ}$ and $165^{\circ} \mathrm{E}$. Almost another $30 \%$ is formed farther east between $165^{\circ} \mathrm{E}$ and $180^{\circ}$. Most of the remainder is formed between $140^{\circ}$ and $150^{\circ} \mathrm{E}$, east of the separation of the Kuroshio from the boundary, with just $5 \%$ of newly formed mode water found west of $140^{\circ} \mathrm{E}$. The volume formed varies from year to year despite the annually repeating surface forcing, indicating that variability is intrinsic to the ocean. The formation volume depends on the outcrop area of the water mass, which is in turn affected by the meandering of the Kuroshio Extension. The large meander of the Kuroshio affects both formation and water properties in the recirculation gyre.

After mode water is formed, it drifts westward with the interior circulation, retaining its properties of temperature, density, and potential vorticity and aging as it moves. In the region closest to the western boundary, region 2, the average age of mode water is $5.2 \mathrm{yr}$, while between $165^{\circ} \mathrm{E}$ and $180^{\circ}$ the average age of mode water is $3.0 \mathrm{yr}$. These ages were determined using the ideal age tracer and are supported by analysis of model CFC fields. TTDs also showed westward propagation of recently ventilated water. These model results are in agreement with observational estimates of mode water age from CFCs (Warner et al. 1996). These estimates do, however, exceed previous estimates of mode water age based on apparent oxygen utilization (Suga et al. 1989), and the CFC estimates from observations were presented as upper limits. For this reason, further analysis is necessary to determine whether these mode water ages are realistic or whether mixing with surrounding (older) waters has increased the tracer value artificially.

These characteristics and variability, although statistically significant in the present analysis, may be harder to observe in a real ocean with annually varying atmospheric forcing. It is unclear whether the signals could be distinguished from the wind and heat-forced variability. Additionally it is certainly a possibility that the time scales of the model are slower than those in reality. These are questions that can only be answered with further analysis, such as performing a similar study on a model forced with an interannually varying atmosphere.

Acknowledgments. The model integrations were performed at the National Center for Atmospheric Research, which is supported by the National Science Foundation. E.M.D. acknowledges support of the Doherty Foundation and National Science Foundation (OCE-0849808). S.R.J was sponsored by the National Science Foundation (OCE-0849808). Participation of S.P. and F.B. was supported by the National Science Foundation by its sponsorship of the National Center for Atmospheric Research. The simulation was performed at the National Center for Computational Sciences at Oak Ridge National Laboratory with computer time awarded under the INCITE program and at the National Center for Atmospheric Research Computational and Information Systems Laboratory.

\section{REFERENCES}

Doney, S. C., and J. L. Bullister, 1992: A chlorofluorocarbon section in the eastern North Atlantic. Deep-Sea Res., 39, 18571883.

England, M. H., 1995: The age of water and ventilation timescales in a global ocean model. J. Phys. Oceanogr., 25, 2756-2777.

Hanawa, K., 1987: Interannual variations of the winter-time outcrop area of subtropical mode water in the western North Pacific Ocean. Atmos.-Ocean, 25, 358-374.

_ , and T. Suga, 1995: A review on the subtropical mode water in the North Pacific (NPSTMW). Biogeochemical Process and Ocean Flux in the Western Pacific, H. Sakai and Y. Nozaki, Eds., Terra Scientific, 613-627.

_ , and J. Kamada, 2001: Variability of core layer temperature (CLT) of the North Pacific subtropical mode water. Geophys. Res. Lett., 28, 2229-2232.

Kawabe, M., 1995: Variations of current path, velocity, and volume transport of the Kuroshio in relation with the large meander. J. Phys. Oceanogr., 25, 3103-3117. 
Large, W. G., and S. G. Yeager, 2009: The global climatology of an interannually varying air-sea flux data set. Climate Dyn., 33, 341-364.

Maltrud, M. E., F. O. Bryan, and S. Peacock, 2010: Boundary impulse response functions in a century-long eddying global ocean simulation. Environ. Fluid Mech., 10, 275-295.

Masuzawa, J., 1969: Subtropical mode water. Deep-Sea Res., 16, 463-472.

Murray, R., 1996: Explicit generation of orthogonal grids for ocean models. J. Comput. Phys., 126, 251-273.

Oka, E., 2009: Seasonal and interannual variation of North Pacific Subtropical Mode Water in 2003-2006. J. Oceanogr., 65,151-164.

Peacock, S., and M. E. Maltrud, 2006: Transit-time distributions in a global ocean model. J. Phys. Oceanogr., 36, 474-495.

Qiu, B., and W. Miao, 2000: Kuroshio path variations south of Japan: Bimodality as a self-sustained internal oscillation. J. Phys. Oceanogr., 30, 2124-2137.

- , and S. Chen, 2005: Variability of the Kuroshio Extension jet, recirculation gyre, and mesoscale eddies on decadal time scales. J. Phys. Oceanogr., 35, 2090-2103.

— North Pacific Subtropical Mode Water: Oceanic versus atmospheric control. J. Phys. Oceanogr., 36, 1365-1380.

Rainville, L., S. R. Jayne, J. L. McClean, and M. E. Maltrud, 2007: Formation of subtropical mode water in a high-resolution ocean simulation of the Kuroshio Extension region. Ocean Modell., 17, 338-356.

Smith, R., and P. Gent, 2002: Reference manual for the Parallel Ocean Program (POP), ocean component of the Community
Climate System Model (CCSM2.0 and 3.0). Los Alamos National Laboratory Tech. Rep. LA-UR-02-2484. [Available online at http://www.ccsm.ucar.edu/models/ccsm3.0/pop.]

Suga, T., and K. Hanawa, 1990: The mixed-layer climatology in the northwestern part of the North Pacific subtropical gyre and the formation area of subtropical mode water. J. Mar. Res., 48, $543-566$.

— subtropical mode water in the $137^{\circ} \mathrm{E}$ section. J. Phys. Oceanogr., 25, 1012-1017.

$\longrightarrow$, and $-1995 \mathrm{~b}$ : The subtropical mode water circulation in the North Pacific. J. Phys. Oceanogr., 25, 958-970.

,,-- and Y. Toba, 1989: Subtropical mode water in the $137^{\circ} \mathrm{E}$ section. J. Phys. Oceanogr., 19, 1605-1618.

_, Y. Takei, and K. Hanawa, 1997: Thermostad distribution in the North Pacific subtropical gyre: The central mode water and the subtropical mode water. J. Phys. Oceanogr., 27, 140-152.

Taneda, T., T. Suga, and K. Hanawa, 2000: Subtropical mode water variation in the northwestern part of the North Pacific subtropical gyre. J. Geophys. Res., 105, 19 591-19 598.

Uehara, H., T. Suga, K. Hanawa, and N. Shikama, 2003: A role of eddies in formation and transport of North Pacific subtropical mode water. Geophys. Res. Lett., 30, 1705.

Warner, M., J. L. Bullister, D. Wisegarver, R. Gammon, and R. Weiss, 1996: Basin-wide distributions of chlorofluorocarbons CFC-11 and CFC-12 in the North Pacific: 1985-1989. J. Geophys. Res., 101, 20 525-20 542.

Worthington, L. V., 1959: The 18-degree water in the Sargasso Sea. Deep-Sea Res., 5, 297-305. 